\title{
Hypaxial Division of the Myotome
}

National Cancer Institute

\section{Source}

National Cancer Institute. Hypaxial Division of the Myotome. NCI Thesaurus. Code C34189.

The ventrolateral portion of the myotomes, which will form muscles innervated by the ventral rami of the spinal nerves, including small, extensor muscles of the neck and vertebral column, and muscles of the lateral and ventral body wall in the thorax and abdomen. 